\title{
SENSIBILIZAÇÃO AMBIENTAL POR MEIO DE ECO PONTOS
}

\author{
Júnior de Souza Costa ${ }^{1}$
}

Débora Machado Corrêa²

Resumo: Quando o lixo eletrônico é inadequadamente destinado, um grande risco ao meio ambiente é ocasionado. Tendo em vista esta problemática, o objetivo deste trabalho foi fornecer embasamento teórico para facilitar a implantação de projetos de reciclagem em quaisquer instituições de ensino. Desta forma, incentivando a replicação deste tipo de ação no país e incentivando o princípio dos "3 R's" (reduzir, reutilizar e reciclar). O estudo se caracterizou de uma abordagem qualitativa, onde foram realizadas consultas bibliográficas e documentais que permitiram a identificação de práticas que devam ser levadas em consideração antes e durante a implantação dos pontos de coleta de lixo na escola.

Palavras-chave: Resíduos Sólidos; Lixo Eletrônico; Educação Ambiental. E-mail: junior.costa.biologo@gmail.com

2 Departamento de Ciências Biológicas, Universidade Federal de Goiás, Regional Catalão. E-mail: dmc.ufg@gmail.com 


\section{Introdução}

Enfrentamos diversos desafios, na atualidade, dentre eles a questão da manutenção da qualidade ambiental frente ao aumento da geração de resíduos sólidos urbanos (RSU). Dentre os RSUs, destaca-se o lixo eletrônico como uma fração potencialmente nociva ao meio ambiente, quando inadequadamente destinada (COELHO, 2000, p.181; HAKIM et al., 2012, p.2272-2276; SILVA; SPERLING; BARROS, 2014, p.251-262).

Durante as últimas décadas, o consumo de produtos eletrônicos aumentou em todo o mundo e a velocidade com que novidades tecnológicas chegam ao mercado faz com que os equipamentos eletrônicos tenham uma vida útil curta, aumentado a quantidade de eletrônicos descartados (TANSKANEN, 2013, p.1001-1011).

Em uma análise global sobre o avanço da produção de resíduos sólidos no Brasil, podemos verificar que o aumento da produção de RSUs é diretamente proporcional ao crescimento da chamada classe média, ou seja, a melhoria do rendimento da população de baixa renda, possibilita o acesso a bens de consumo, que em última instância, contribuem para o aumento de resíduos gerados (FIESP, 2003). Para Luczkievicz et al., (2015, p.284-299) tal aumento de consumo fez com que a demanda na produção de resíduos líquidos e sólidos tenha se tornado um grave problema ambiental e de saúde pública, uma vez que não foi acompanhada de medidas que aumentem a conscientização da população sobre boas práticas de gerenciamento de resíduos.

Resíduos eletrônicos contêm uma grande quantidade de cobre e de metais preciosos que podem ser reaproveitados, bem como uma abundância de metais pesados, que são perigosos para saúde humana, o que torna tais recursos secundários atraentes e simultaneamente, contaminantes em potencial para o meio no qual são descartados (WIENOLD et al., 2011, p.530535).

Tal potencial de contaminação tornou o descarte deste tipo de resíduo, um dos problemas contemporâneos mais discutidos e a falta de informação sobre a correta destinação de tais resíduos faz com que, muitas vezes, acabem sendo descartados em meio a outros tipos de resíduos, em aterros sanitários e lixões (MATTOS et al., 2008, p.2).

A Lei 12.305/2010 que instituiu a Política Nacional de Resíduos Sólidos apresentou um conjunto de metas e ações relativas à gestão e gerenciamento de resíduos sólidos no Brasil, dispondo sobre diretrizes relativas à gestão e gerenciamento dos resíduos sólidos e definindo os municípios como responsáveis pela observância e cumprimento de ações que garantam o consumo e desenvolvimento sustentável.

O Ministério das Cidades, a Fundação Nacional de Saúde (FUNASA) e a Secretaria de Estado de Meio Ambiente e Desenvolvimento Sustentável (SEMAD), visando colaborar com os municípios, lançaram projetos/recursos financeiros para que os mesmos pudessem construir soluções (aterros Revbea, São Paulo, V. 13, № 1: 140-155, 2018.

revista brasileira educação ambiental 
sanitários, elaboração do plano municipal de gestão de resíduos) visando assim, o cumprimento dos dispositivos legais vigentes (MMA, 2012, p.8).

Com base no exposto acima, o presente estudo se caracteriza de uma abordagem qualitativa, através de consulta a bibliografias e documentos que permitam a identificação de práticas que devam ser levadas em consideração, antes e durante a implantação de pontos de coleta de lixo eletrônico (Eco Pontos) em ambientes escolares, servindo como subsídio para a replicação deste tipo de intervenção, bem como, para a sensibilização de estudantes quanto à importância do descarte correto do lixo e incentivando o princípio dos "3 R's" (reduzir, reutilizar e reciclar).

\section{A importância da coleta seletiva e da reciclagem}

\section{A coleta seletiva no Brasil}

O descarte do lixo eletrônico é de responsabilidade de todos, consumidores, empresas e governo. Mas quando analisamos a quantidade de RSUs gerada e sua natureza, fica evidente que a adequação à legislação vigente, a falta de fiscalização e a falta de informação do consumidor final são fatores importantes que contribuem para o desequilíbrio do meio ambiente.

Segundo a Associação Brasileira de Empresas de Limpeza Pública e Resíduos Especiais (ABRELPE), em 2013, no Brasil, foram geradas 76,4 milhões de toneladas de resíduos sólidos urbanos, das quais 69,1 milhões de toneladas foram coletadas. Deste total, 40,3 milhões teve como destinação final, aterros sanitários, e 28,8 milhões foram parar em lixões. Esta última forma de descarte é considerada inapropriada segundo a legislação, no entanto, a falta de pressão governamental se reflete na morosidade com que os municípios estão se adequando.

Ainda para a ABRELPE (2013) os programas de coleta seletiva no Brasil vêm crescendo sem, contudo, alcançar a taxa com que a produção de resíduos aumenta. A taxa com que o número de municípios brasileiros que são servidos por coleta seletiva vem aumentando em aproximadamente $2,2 \%$ ao ano, enquanto que no mesmo período, a taxa de produção de resíduos aumenta em $4,1 \%$. Nesse sentido, a projeção de universalização da coleta seletiva no Brasil só ocorrerá por volta do ano 2044, se mantido este ritmo.

Para Vilhena e D'Almeida (2000, p. 81-89), a coleta seletiva do lixo, que nada mais é que a separação e coleta de materiais recicláveis na fonte geradora, é um fator determinante para o sucesso da reciclagem. E para que nos domicílios haja eficácia na separação dos resíduos é necessária a participação de cada cidadão (HISATUGO; JÚNIOR, 2007, p. 36-55). É importante destacar que para alcançar tal envolvimento por parte da população é necessário investir em ações de Educação Ambiental, já que é necessário conhecimento e treinamento para se realizar a separação do lixo de acordo com suas categorias. 
No Brasil, a primeira experiência documentada de coleta seletiva de lixo é datada do ano 1985 e ocorreu no bairro de São Francisco, em Niterói (RJ) (FERREIRA et al, 1986, p.355-357). Tal iniciativa se mantém até hoje, como sendo uma referência na disseminação e discussão dessas práticas no país (ADEODATO, 2008, p.6-39; EINGENHEER; FERREIRA, 2015, p.677-684).

Segundo o Instituto Brasileiro de Geografia e Estatística - IBGE (2010), 451 municípios brasileiros (8,2\%) afirmavam desenvolver programas de coleta seletiva, até o ano de 2010 (Tabela 1).

Tabela 1: Número de municípios com programas de coleta seletiva de lixo, por região brasileira, até 2010.

\begin{tabular}{l|c|c|c|c}
\hline & \multicolumn{2}{|c|}{ Número de municípios } & \multicolumn{2}{c}{ \% de programas em relação } \\
\multicolumn{1}{c|}{ Região } & Por região & $\begin{array}{c}\text { Com coleta } \\
\text { seletiva }\end{array}$ & Brasil & Região \\
\hline Norte & 449 & 1 & 0,2 & 0,2 \\
\hline Nordeste & 1.787 & 27 & 6 & 1,5 \\
\hline Sudeste & 1.666 & 140 & 31 & 8,4 \\
\hline Sul & 1.159 & 274 & 60,8 & 23 \\
\hline Centro-Oeste & 446 & 9 & 2 & 2 \\
\hline Brasil & 5.507 & 451 & 8,2 & - \\
\hline
\end{tabular}

Fonte: Adaptado de IBGE (2010).

Conforme o artigo 33 da Lei 12.305/2010, as empresas produtoras de produtos tais como pilhas, baterias, lâmpadas, produtos eletroeletrônicos e seus componentes são responsáveis pelo recolhimento de tais materiais após a utilização do consumidor, independentemente do serviço público de limpeza urbana.

Contudo, segundo Miguez (2010, p.24), cerca de $75 \%$ dos produtos eletrônicos obsoletos estão mantidos nas residências, em parte, porque a população desconhece como descartá-los. Assim, a falta de informação do consumidor e falta de fiscalização empresarial, no que tange à logística reversa de produtos tecnológicos, são fatores importantes que diminuem 0 reaproveitamento destes materiais ou que levam a seu descarte inapropriado.

\section{A reciclagem no Brasil}

A atividade de coleta e de reaproveitamento de resíduos e outros materiais representa uma atividade comercial, que ao longo do tempo sofreu altos e baixos, acompanhando as demandas do mercado (ABRELPE, 2011) e vem ganhando força após o movimento ambiental da década de 70, impulsionada como atividade de conservação ambiental (ERASMUS, 1980, p.5-13; MARSHALL; FARAHBAKHSH, 2013, p.988-1003).

Este avanço, no entanto, começou a se solidificar somente após a Conferência das Nações Unidas Sobre o Desenvolvimento, em 1992, na qual a 
reciclagem passou a integrar a agenda de gerenciamento dos resíduos sólidos urbanos como o terceiro "R" formando assim, um dos pilares do princípio dos "3 R's" (EIGENHEER; FERREIRA, 2015, p.677-684).

Segundo Russo (2003, p.7-10), a reciclagem é um dos componentes mais importantes para se solucionar os problemas relativos ao acúmulo de lixo, pois através dela, novos produtos podem ser produzidos a partir de material já usado, atendendo à crescente demanda da sociedade por novos produtos, reduzindo o acúmulo de resíduos e contribuindo na preservação dos recursos naturais.

Até 2012 , cerca de $13 \%$ dos resíduos urbanos eram reciclados no Brasil, no entanto, o potencial para reciclagem é muito maior. Dados projetados pelo Instituto de Pesquisa Econômica Aplicada - IPEA, demonstraram, que da fração seca dos resíduos recicláveis coletados nas cidades brasileiras, apenas $27 \%$ foram efetivamente recuperados em 2012, ou seja, foram desviados dos lixões e aterros sanitários, retornando à atividade produtiva (CEMPRE, 2013).

Um levantamento realizado nos EUA pela Environmental Protection Agency (EPA), em 2015, estimou que cerca de três quartos dos computadores vendidos, em desuso, estejam armazenados em garagens e armários de residências. Ainda, de acordo com a EPA, mais de 4,6 milhões de toneladas de lixo eletrônico acabaram em aterros dos EUA apenas no ano 2000. Estas estimativas apontam que existe uma barreira que ainda não foi contornada em relação à reciclagem do lixo tecnológico e ainda causam preocupação em relação à liberação de substâncias tóxicas no meio ambiente, em decorrência da destinação inapropriada deste tipo de resíduo (EPA, 2015).

De acordo com o Instituto Claro (2015), a reciclagem de uma tonelada de lixo eletrônico evita a emissão de três toneladas de $\mathrm{CO}_{2}$. Portanto, a reciclagem de lixo eletrônico além de evitar a contaminação de solos e do lençol freático também ajuda no combate ao aquecimento global.

O'leary e Walsh (1999, p. 372), argumentam que a reciclagem de resíduos sólidos não serve apenas para conscientizar a população sobre as questões ambientais, mas deve ser vista como uma alternativa viável, que pode gerar emprego e renda para a comunidade envolvida.

\section{Planejamento e etapas do projeto}

\section{Envolvimento coletivo}

A implantação de um ponto de coleta seletiva não é uma ação simples de ser realizada e dependerá do trabalho de um coletivo de pessoas, assim, o primeiro passo para a realização é buscar um grupo de pessoas que estejam interessadas em fazer o trabalho (SMASP, 2001).

Sidique et al., (2010, p.163-170) apontam que no planejamento e na implantação de um projeto de coleta seletiva, a principal dificuldade encontrada 
é a participação da sociedade, pois ela é o fator determinante para definir o investimento que será realizado.

Neste contexto, estimular a participação da comunidade escolar é fundamental para que possamos assegurar que as propostas e objetivos do projeto sejam realizados de maneira democrática dentro da rotina escolar (TRISTÃO, 2005, p.251-264; BIZERRIL; FARIA, 2001, p.57-69).

Além disso, o Sistema Ambiental Paulista e a SMASP (2001) elencam alguns pontos que devem receber atenção antes da implantação de projetos que envolvam reciclagem, tais como: 1) enumerar os envolvidos (participantes); 2) identificar o caminho o lixo percorrerá até o destino final; 3) delimitar as instalações físicas de armazenagem e locais intermediários; 4) contactar possíveis responsáveis pela coleta; 5) determinar a frequência da coleta; 6) conhecer o mercado de recicláveis (possibilidades de doação ou venda); 7) determinar que tipo de material será coletado (todo tipo de materiais recicláveis ou apenas os mais fáceis de serem comercializados); 8) desenvolver ações de Educação Ambiental (identificar parcerias); 9) verificar quais informações cada segmento deve receber; e 10) pensando em cada segmento e as informações passadas, planejar as atividades que serão desenvolvidas visando atingir ao objetivo proposto.

É importante complementar que o progresso e a valia dos projetos são uma incitação para que a Educação Ambiental seja real no cotidiano das escolas. A metodologia de construção de uma acessão pedagógica no dia-a-dia escolar será necessária considerando o meio e as práticas de aprendizagem de cada ambiente escolar (COSTA, et al., 2008, p.133-144).

Determinar se o reaproveitamento do material coletado será total ou parcial depende do número de pessoas envolvidas no projeto e no conhecimento do mercado de recicláveis da região. Para que haja uma destinação final adequada dos resíduos não aproveitáveis, a princípio devemos identificar o resíduo que será coletado e conhecer um pouco sobre sua composição, a fim de evitar possíveis problemas à saúde humana, relacionados à manipulação de componentes e também de evitar contaminação do meio ambiente, causada pela má destinação dos mesmos. Na Tabela 2 (próxima página) são apresentados potenciais riscos à saúde humana, ocasionados por elementos tóxicos presentes em lixo eletrônico descartado indevidamente.

Recomenda-se também envolver amigos e familiares, para que eles deem um destino correto a seus celulares, baterias, carregadores, chips e fones de ouvido obsoletos. Certamente, um projeto como esse, não caminhará sozinho, mas terá que envolver a participação do máximo de pessoas possível, assim, deve-se recrutar o apoio de professores, alunos, funcionários da limpeza, além da coordenação pedagógica da escola. O envolvimento coletivo propõe o despertar de uma simetria entre os envolvidos e reforça a importância da escola como espaço de transformação social (COSTA, et al., 2008, p.15171256). 
Tabela 2: Potenciais efeitos de metais pesados, comumente associados a lixo eletrônico, sobre a saúde humana.

\begin{tabular}{|c|c|}
\hline Elemento & Risco à saúde humana \\
\hline Alumínio & Favorece a ocorrência do mal de Alzheimer \\
\hline Arsênio & $\begin{array}{l}\text { Acumula-se nos rins, fígado, sistema gastrointestinal, baço, pulmões, ossos e } \\
\text { unhas, podendo apresentar efeito cancerígeno. }\end{array}$ \\
\hline Bário & $\begin{array}{l}\text { Possui efeito vasoconstritor, causando problemas cardíacos e pode afetar o } \\
\text { sistema nervoso central. }\end{array}$ \\
\hline Cádmio & Acumula-se nos rins, fígado, pulmões, pâncreas, testículos e coração. \\
\hline Chumbo & $\begin{array}{l}\text { Causa dores de cabeça e anemia, mesmo em baixas concentrações; afeta os } \\
\text { sistemas nervoso, renal e hepático. }\end{array}$ \\
\hline Cobre & Afeta o fígado. \\
\hline Mercúrio & Causa lesões no cérebro e malformação de fetos durante a gravidez. \\
\hline Níquel & Possui efeito cancerígeno. \\
\hline
\end{tabular}

Fonte: Adaptado de Secretaria de Meio Ambiente de São Paulo (2016).

Nesse contexto, Bermudez e Longhi (2008, p. 57-69) complementam que a gestão de propostas metodológicas envolvendo Educação Ambiental e a sociedade deve ser repensada, pois a transferência de conhecimento científico não é de responsabilidade apenas da esfera das ciências e biologia, mas sim das mais diferentes áreas, podendo assim, contribuir para a construção de uma prática social coletiva.

\section{Conhecer o mercado de recicláveis - doação e venda}

Embora tenha ocorrido uma rápida evolução do mercado de eletrônicos no Brasil, ainda não existe uma legislação que regulamente com eficiência o descarte de produtos e lixos eletrônicos, estabelecendo obrigações para evitar a destinação inapropriada. Dar fim a esse material, livrar o meio ambiente e a saúde pública torna-se cada vez mais inadiável (CEDIR, 2016).

A SMASP (2001) propõe dois meios disponíveis no mercado para recepção do material coletado, a doação e a venda. A doação é uma ótima opção quando se identifica na região cooperativas ou associações que já vendam ou reutilizem o tipo de material coletado. A doação diminui a mão de obra dos envolvidos na coleta, uma vez que a necessidade de separar componentes é eliminada, já que a cooperativa que recebe o material se incumbirá deste trabalho. Já no caso da venda é necessário identificar empresas que possuam interesse na compra de material reciclável e verificar se a quantidade de material coletado resultará num ganho que atenda aos interesses do projeto. A SMASP disponibiliza em sua página virtual uma lista de endereços eletrônicos com páginas de ONGs e associações que disponibilizam preços para compra de material recicláveis. Além disso, Revbea, São Paulo, V. 13, № 1: 140-155, 2018. 
compradores também poderão ser encontrados em listas telefônicas ou entidades como a da secretaria de meio ambiente do município, prefeitura ou órgãos afins.

\section{Identificar empresas de coleta e reciclagem de materiais}

Para Hisatugo e Júnior $(2007,205-216)$ o maior problema que impede o sucesso da reciclagem no Brasil se dá pela natureza estrutural e a necessidade de acabar a tributação em cima dos reciclados, já que esta eleva os custos, desestimulando a reciclagem. Também, segundo os autores, as taxas tributárias dos materiais reutilizados já foram pagas na primeira cadeia de produção, assim cobrar tributos em cima de tais materiais é abusivo.

Antes de desenvolver um projeto de reciclagem é de grande importância que seja realizada uma pesquisa dentro da cidade ou nas proximidades para se verificar se existem empresas especializadas na coleta do material selecionado, pois sem o estabelecimento da parceria com uma empresa, os pontos de coleta não atingiriam o objetivo da reciclagem.

Uma opção é entrar em contato com o fabricante do produto que se pretende coletar, a central de atendimento ao consumidor saberá informar um local adequado para destinação do lixo eletrônico. Outra alternativa é procurar umas das iniciativas a seguir, conforme sugere o Instituto Claro (2015):

- Ciclo Sustentável Philips - o programa já atende 25 cidades brasileiras. A empresa se responsabiliza pela coleta e destinação correta de todos os tipos de aparelhos eletroeletrônicos e eletrodomésticos da marca, como tevês, aparelhos de áudio e vídeo e cafeteiras. No site, você encontra o mapa com os postos de coleta: www.sustentabilidade.philips.com.br

- DELL, HP, Positivo e Itautec - essas empresas possuem programas de reciclagem dos produtos de suas marcas e fazem a coleta do equipamento que não está mais sendo usado. O serviço é gratuito, mas precisa ser agendado por telefone ou e-mail. Informe-se nos sites das empresas.

Centro de Descarte e Reuso de Resíduos de Informática, CEDIR/ USPrecebe e reforma equipamentos como CPUs, monitores, impressoras, scanners, projetores e aparelhos de fax e os encaminha para unidades da USP e entidades assistenciais cadastradas em São Paulo. www.cedir.usp.br

- Projeto Computadores para Inclusão $(\mathrm{Cl})$ - projeto do Governo Federal que recupera computadores descartados por órgãos governamentais, empresas e pessoas físicas. Os equipamentos são enviados aos centros de recondicionamento de computadores, que também promovem a capacitação e a inclusão digital de jovens. Depois de recuperados, os 
aparelhos são encaminhados a escolas públicas, bibliotecas e tele centros comunitários. www.computadoresparainclusao.gov.br

- Walmart - a rede de supermercados tem mais de 60 pontos de coleta de pilhas e baterias em todas as suas lojas e clubes e garante a destinação correta desses produtos. www.walmartbrasil.com.br

Além desses pontos de coleta, a ONG Programando o Futuro que abrange a região metropolitana de Brasília-DF e algumas cidades do interior de Goiás, possui uma rede de postos de coleta onde qualquer pessoa pode descartar corretamente seus equipamentos e resíduos eletroeletrônicos em geral, tais como: computadores, impressoras, celulares, televisores, fios, mídias de CD e DVD, entre outros. A seguir apresentamos a relação desses postos indicados pela ONG:

- Eco Mercado Bioon - Endereço: Asa Norte, CLN 303 Bloco B Loja 06 - Asa Norte, telefone: (62) 3326-2944.

- ANA. Agencia Nacional de Águas - Asa Sul, Setor Policial Sul, ao lado da ABIN.

- Centro de Diversidade Cultural Espaço 35 - Entre quadras $112 / 312$ Sul. Telefone: (62) 3346-4065.

- Estação Digital - Ed. Venâncio IV, sala 105 e 106. Telefone: (62) 8457-5281.

- Superior Tribunal de Justiça - Praça dos Três Poderes, recepção, térreo.

- Gabinete Popular - Ceilândia, QNN 17 Conjunto "E" lote 46, Ceilândia Norte. Telefone: (62) 3048-2633.

- Gama - Endereço: EQ 12/16 Setor Oeste, Gama-DF. Telefones: (62) 3901-8078 e (62) 3901-8293.

- Núcleo Bandeirante - Visão Madeira e Materiais de Construção. 3a Avenida AE 13 Lt. P/Q. Telefone: (62) 3386-1066.

- Região Metropolitana - Cidade Ocidental, Secretaria do Meio Ambiente. Endereço: SQ 16, Qd 11, lote 20 - salas 01 e 02. Telefone: (62) 3625-3209.

- Cristalina - Cooperativa Rede Terra. BR 040, Km 95, ao lado do Hotel Cata-ventos. Telefones: (61) 3612-2912 e (61) 3612-6319.

- Formosa - Instituto Itiquira. Rua Visconde de Porto Seguro, 843 Centro. Telefone: (61) 3631-0933.

- Valparaíso - Estação de Metarreciclagem. Área Especial, Lote "B" antigo Ginásio de Esportes. Etapa B. Telefone: (61) 3223-8996. 
Segundo a ONG, depois de recolhidos os equipamentos, a equipe realiza o desmanche dos equipamentos e a separação por resíduos de acordo com sua propriedade. Posteriormente, esses resíduos, que em sua maioria são plásticos, ferro, alumínio, borracha, vidro, cobre e placa de circuito, são reciclados por empresas licenciadas e que realizam o projeto de maneira ambientalmente correta (ONG Programando o Futuro, 2016).

Sendo assim deverá ser montada a parte operacional do projeto que se trata da implantação do mesmo dentro da instituição escolar.

\section{Operacionalização do projeto}

Nesse ponto deverão ser levados em consideração: 1) $O$ que irá ser coletado? 2) Onde será armazenado? 3) Quem irá coletar os resíduos? 4) Com que frequência será coletado? 5) Para onde será destinado?

Embora este trabalho sugira que o material coletado seja lixo eletrônico ou lixo tecnológico, com o passar do tempo o material coletado poderá ser alterado de maneira a refletir as demandas da comunidade. No entanto é importante delimitar um tipo de material, tendo em vista que é através dele que poderemos identificar quem o coletará.

Se o material selecionado for papel, latas de alumínio e papelão, estes poderão ser coletados por empresas de reciclagem, ONGs, associações de catadores, etc. No caso do lixo eletrônico deve ser levado em conta que a manipulação dos materiais deve ter cuidados especiais e os resíduos coletados deverão ser entregues a uma empresa qualificada que possa lhes dar destinação final adequada.

A partir de então, poderá ser discutido de que forma será feita a entrega do material coletado. Se será doado ou vendido, dependerá do propósito a que se buscando atender, a ação da coleta poderá objetivar à efetivação da cidadania através da Educação Ambiental no ambiente escolar. Também poderá buscar retorno financeiro para ser aplicado em outros projetos desenvolvidos pela escola. Isso competirá a coordenação da instituição decidir.

O espaço físico e alocação do material para reciclagem configura um dos maiores problemas para os pequenos empreendedores da reciclagem de materiais, segundo autores da área de logística reserva e gerenciamento de resíduos sólidos (HUANG et al., 1998, p.36-55; CHANG; WEI, 2000, p.133-149; BHAT, 1996, p.87-96; TUNG; PINNOI, 2000, p.449-468).

Recomenda-se que o material seja coletado frequentemente, com uma periodicidade que seja adequada ao volume de material que será transportado até o local da destinação. Também deve ser considerado que o fluxo dos resíduos provenientes do Eco Ponto será armazenado dentro da própria escola até que seja dada sua destinação final, assim a frequência de coleta deve estar adequada à capacidade de armazenamento da instituição envolvida.

revista brasileira educação ambiental 


\section{Implantação}

Segundo as orientações da SMASP (2001) disponíveis em uma cartilha desenvolvida pela Secretaria de Meio Ambiente de São Paulo, a implantação é parte crucial que contribui efetivamente para o desenvolvimento do programa, onde a divisão das atividades garantirá o objetivo do projeto. Nessa etapa deverão ser tomadas as providências acertadas: 1) Compras, se for necessário; 2) Confecção de placas e cartazes 3) Instalação dos Eco Pontos de coleta; 4) Treinamento e capacitação dos envolvidos; 5) Elaboração de folhetos e folders informativos; e 6) Inauguração do projeto.

Para Santos et al., (2014, p. 780-791) a implantação de Eco Pontos em escolas é de grande valor e necessidade, tendo em vista que ajuda a sensibilizar os alunos e a sociedade, mostrando que há uma solução para o lixo eletrônico através da reciclagem.

\section{Identificação dos pontos de coleta}

Poderá ser utilizado qualquer meio para a coleta dos resíduos, como tambores, contêineres, caixas de papelão, lixeiras, etc. Isso dependerá do material disponível na escola. Esses recipientes serão identificados com adesivos do projeto, bem como, indicados por placas ou cartazes que contenham instruções sobre os tipos de materiais que podem ser depositados.

Os pontos deverão ser implantados em pontos de maior visibilidade dentro da escola, a fim de estimular a participação de todos.

A utilização de recipientes de coleta reutilizados é indicada pelo baixo custo, bem como para incentivar o reaproveitamento, o que demonstra a efetivação do objetivo do projeto.

\section{Divulgação do projeto}

É de tamanha importância que durante toda a realização do projeto, as pessoas da comunidade e os envolvidos no processo sejam informados sobre os passos que serão tomados (SMASP, 2001).

Poderá ser realizado um evento com exposição de produtos eletrônicos antigos tais como: celulares, computadores, máquinas de escrever, disquetes, CDs, entre outros.

Também poderá ser feito um ciclo de palestras com as informações e objetivos do projeto, com foco na sustentabilidade e conservação do meio ambiente, podendo também ser aplicados minicursos e oficinas de reciclagem. O importante é que esse evento seja alegre, marcante e cause um impacto positivo nos alunos.

Segundo Costa (2012, p.133-144), o cidadão pode conhecer e entender melhor o significado do mundo através de ações de Educação Ambiental que 
modifiquem a sociedade, instruindo o cidadão e a sociedade para 0 bem comum, visando à sustentabilidade do planeta.

Complementando, a Lei 9.795 de 27 de abril de 1999, prevê que instituições educacionais públicas e privadas, órgãos públicos, estados e municípios, além de instituições e organizações não governamentais, deverão promover a Educação Ambiental em todos os níveis do ensino, promovendo ações de mobilização e sensibilização da sociedade.

\section{Manutenção do projeto}

Deverão ser levados em consideração os seguintes processos: 1) Acompanhamento e gerenciamento das coletas, armazenamento, venda ou doação; 2) Levantamento das quantidades de material coletado (setorial, por tipo de material); 3) Receita gerada (caso o material tenha sido vendido); 4) Atividades contínuas de sensibilização e informação; 5) Resultados do projeto

É importante que a divulgação do projeto seja contínua, através de palestras, feiras de ciências, gincanas, reuniões, cartazes e exposições que aumentem a visibilidade da ação e que permita aos novos membros da comunidade tornarem-se cientes. Nesses eventos também poderão ser divulgados 0 balanço do projeto, destacando os resultados positivos e avaliando-se os pontos a serem melhorados no andamento das atividades. (SMASP, 2001).

\section{Considerações Finais}

Identificou-se nas pesquisas que o trabalho coletivo, bem como as ações a serem realizadas para implantação de um projeto dentro de uma escola vão muito além do recolhimento dos resíduos.

A coleta seletiva por si só não promove a sustentabilidade do meio ambiente, devemos buscar a formação de parcerias entre sociedade, escola, indústria e comércio, pois elas são indispensáveis para efetivação da Política Nacional de Resíduos Sólidos, tão quanto é importante a integração de ações políticas e de planejamento.

Neste sentido, a Educação Ambiental tem um papel importante na mudança de valores e padrões comportamentais da sociedade. E consequentemente, a promoção do desenvolvimento sustentável das nossas cidades, garantindo a utilização parcimoniosa dos recursos naturais e da qualidade de vida das gerações futuras. 


\section{Referências}

ABRELPE. Associação Brasileira de Empresas de Limpeza Pública e Resíduos especiais. Panorama de Resíduos Sólidos no Brasil - 2011. São Paulo, 186 p., 2011.

ABRELPE. Associação Brasileira de Empresas de Limpeza Pública e Resíduos especiais. Estimativas dos custos para viabilização da destinação adequada de resíduos sólidos no Brasil. São Paulo, 2013.

ADEODATO, S. Reciclagem, ontem, hoje, sempre. São Paulo: CEMPRE. São Paulo, p. 6-39, 2008.

BERMUDEZ, G.; LONGHI, A.L. La educación ambiental y la ecologia como ciência: uma discusión necesaria para la enseñanza. Revista Electrónica de Enseñanza de lãs Ciências, Espanha, v. 7, n. 2, p. 275-297, 2008.

BHAT, V.N. A model for the optimal allocation of trucks for the solid waste management. Copenhagen-DK. Waste Management \& Research, v. 14, p. 8796, Jan., 1996.

BIZERRIL, M.X.A.; FARIA, D.S. Percepção de professores sobre a Educação Ambiental no ensino fundamental. Revista Brasileira de Estudos Pedagógicos, Brasília, v. 82, n. 200, p. 57-69, jan/dez, 2001.

BRASIL, Instituto Brasileiro de Geografia e Estatística - IBGE, 2010. Disponível em: http://www.censo2010.ibge.gov.br/dados divulgados/index.php?uf=25. Acesso em: 14 Mar. 2016.

BRASIL. Instituto Brasileiro de Geografia e Estatística - IBGE, 2008. Disponível em:http://www.ibge.gov.br/home/estatistica/populacao/condicaodevida/pnsb200 8/default.shtm. Acesso em 28 fev. de 2016.

BRASIL. Lei no 9.795, de 27 de abril de 1999. Dispõe sobre a Educação Ambiental, institui a Política Nacional de Educação Ambiental e dá outras providências. Diário Oficial [da República Federativa do Brasil], Brasília, DF, 29 abr. 1999. Disponível em: http://www.planalto.gov.br/ccivil 03/leis/l9795.htm. Acesso em: 17 Mar. 2016.

BRASIL. Política Nacional de Resíduos Sólidos, Lei 12.305. Diário Oficial da República Federativa do Brasil, Brasília, DF, 2 ago. 2010. Disponível em: http://www.planalto.gov.br/ccivil 03/ ato2007-2010/.../lei/l12305.htm. Acesso em: 22 Mar. 2016.

CEDIR. Centro de Descarte e Reuso de Resíduos de Informática. Equipamentos elétricos e eletrônicos ainda têm destino incerto e representam risco de contaminação. Prefeitura do Campus USP capital. 2016. Disponível em: https://eco4u.wordpress.com/tag/lixo-eletronico/page/2/ Acesso em 17 de Mar. 2016. 
CEMPRE, Compromisso Empresarial Para a Reciclagem. CEMPRE Review. 2013. Disponível em: < http://cempre.org.br/artigo-publicacao/artigos> Acesso em: 18 Maio. 2016.

CHANG, N.; WEI, Y. Siting recycling drop-off in urban area by genetic algorithm-based fuzzy multi objective nonlinear integer programming modeling. Fuzzy Sets and Systems. Nagoya-JP. v. 114, n. 1, p. 133-149, Aug. 2000.

COELHO, H. Gerenciamento de resíduos de serviços de saúde: Manual de Gerenciamento de Resíduos Sólidos de Serviços de Saúde. Rio de Janeiro: CICT/FIOCRUZ, p. 871. 2000.

COSTA, J.C.O. Educação Ambiental, um Direito Social Ambiental. 2012. Disponível em: http://www.mp.sp.gov.br/portal/page/portal/cao infancia juventude/doutrina/dou trinas artigos/EDUAMB-DIRSOCFUNDA.doc. Acesso em: 17 Mar. 2016.

COSTA, M.F.B.; MONTEIRO, S.C.F; COSTA, M.A.F. Projeto de Educação Ambiental no ensino fundamental: bases para práticas pedagógicas. Revista do PPGEA/FURG-RS, ISSN 1517-1256, v. 21, 2008.

EIGENHEER, E.M.; FERREIRA, J. A. Três décadas de coleta seletiva em São Francisco (Niterói $/ R J$ ): lições e perspectivas. Revista Engenharia Sanitária Ambiental, v.20 n.4, p. 677-684, 2015.

EPA. Environmental Protection Agency USA. Unpublished laboratory data of the Environmental Research Laboratory. Ambient Water Quality Criteria for Dichlorobenzene, US-EPA Technical Report 440/5-80-040a, Wahington, D.C., USA, 2015. Disponível em: <http://www.epa.ie/\#\&panel1-1> Acesso em: 17 de Mar. 2016.

ERASMUS, J.H. Recycling in the OECD and European Communities. Research Recovery and Conservation, v.5, p. 5-13, 1980.

FERREIRA, J.A.; EIGENHEER, E.M.; SERTÃ, F. Experiência Piloto de Coleta Seletiva. Revista Engenharia Sanitária e Ambiental. v.25, p. 355-357, 1986.

FIESP - Federação das Indústrias do Estado de São Paulo. Indicadores de desempenho ambiental da indústria. São Paulo: Fiesp/Ciesp, 2003. Disponível em: < http://www.fiesp.com.br/> Acesso em: 12 de Jan. 2016.

HAKIM, S.T.; TAYYAB, S.M.H.; SHAFIQ, A.; NADEEM, S.G. Reuses of syringes: a social crime related to health care waste management. African Journal of Microbiology Research, v. 6, n. 10, p. 2272-2276, 2012.

HISATUGO, E; JÚNIOR, O.M. Coleta seletiva e reciclagem como instrumentos para conservação ambiental. Revista Sociedade e natureza. 19 (2): 205-216, 2007.

HUANG, G.H.; BAETZ, B.W.; PATRY, G.G. Trash-Flow Allocation: Planning Under Uncertainty. Interfaces. Hanover-MD-USA. v. 28, n. 6, p. 36-55, Jun. 1998.

revista brasileira educação ambiental 
INSTITUTO CLARO. Lixo eletrônico - qual o melhor destino para ele? Cartilha Claro Recicla, São Paulo, 2015.

LUCZKIEVICZ, C; MENEGAT, M.O; FIGUEIREDO, A.M.B. Destinação de resíduos sólidos gerados por empresas metalúrgicas localizadas no município de Chapecó - SC. Revista Tecnológica. V.3 oㅡ 2, p. 284-299, 2015.

MARSHALL, R.E.; FARAHBAKHSH, K. Systems approaches to integrated solid waste management in developing countries. Waste Management, v. 33 p. 988-1003, 2013.

MATTOS, K.M.C.; MATTOS, K.M.C.; PERALES, W.J.S. Os impactos ambientais causados pelo lixo eletrônico e o uso da logística reversa para minimizar os efeitos causados ao meio ambiente. Anais do XXVIII Encontro Nacional de Engenharia de Produção, 2008, p. 2.

MIGUEZ, E.C. Logística Reversa como solução para o problema do lixo eletrônico: benefícios ambientais e financeiros. Rio de Janeiro: Qualitymark, 2010.

MMA, Ministério do Meio Ambiente. Contextos e Principais Aspectos. p. 8, 2012. Disponível em: http://www.mma.gov.br/cidades-sustentaveis/residuossolidos/politica-nacional-de-residuossolidos/contextos-e-principais-aspectos.

Acesso em: 14 Mar. 2016.

O'LEARY, P.R.; WALSH, P.W. Decision Maker's Guide to Solid Waste Management. v.2. 2.ed. Washington DC: U.S. Environmental Protection Agency. 372p. 1999.

OLIVEIRA, A.L.; OBARA, A.T.; RODRIQUES, M.A. Educação Ambiental: concepções e práticas de professores de ciências do ensino fundamental. Revista Electrónica de Enseñanza de lãs Ciências, Espanha, v.6, n. 3, p. 471-495, 2007.

ONG PROGRAMANDO O FUTURO. Encontre o posto de descarte de lixo eletrônico mais próximo. Valparaíso de Goiás - GO, 2016. Disponível em: http://www.programandoofuturo.org.br/site novo/2010/. Acesso em: 17 de Mar. 2016.

RIBEIRO, T. F. Coleta seletiva de lixo domiciliar. Caminhos da Geografia 1(2) p.50-69, 2000.

RUSSO, M.A.T. O aterro sanitário na base de uma gestão integrada de resíduos sólidos. Anais do VI SILUBESA, Florianópolis, Brasil, 2003.

SANTOS, D. T.; DIAS, G.M.; SANTOS, R.P.A.; SILVA, U.B.; PAULA, V.V. Estratégias de gestão no destino do lixo tecnológico: um caso de implantação de um Eco Ponto na UNIGRANRIO. Anais do XVII Simpósio de Pesquisa Operacional e Logística da Marinha - SPOLM 2014 [Blucher Engineering Proceedings, n1, v.1, p.780-791 São Paulo: Blucher, 2014. 
SÃo PAUlO (ESTAdO) SECRETARIA DO MEIO AMBIENTE. Potenciais efeitos de metais pesados oriundos de lixo eletrônico sobre a saúde humana. São Paulo, 2016.

SIDIQUE, S.F.; JOSHI, S.V.; LUPI, F. The effects of behavior and attitudes on drop-off recycling activities. Resources, Conservation and Recycling, v. 54, n. 3, p. 163-170, 2010.

SILVA, D.F.; SPERLING, E.V.; BARROS, R.T.V. Avaliação do gerenciamento dos resíduos de serviços de saúde em municípios da região metropolitana de Belo Horizonte - Brasil. Revista de Engenharia Sanitária e Ambiental, v. 19, n. 3, p. 251-262, 2014.

SMASP - SECRETARIA MUNICIPAL DE ADMINISTRAÇÃO PÚBLICA DE SÃO PAULO. Projeto Coleta Seletiva (Sistema Ambiental Paulista). Cartilha SMASP, 2001.

TANSKANEN, P. Management andrecy clingof electronic waste. Acta Materialia, Finland, v.61, p.1001-1011, 2013.

TRISTÃO, M. Tecendo os fios da Educação Ambiental: o subjetivo e o coletivo, o pensado e o vivido. Educação e Pesquisa, São Paulo, v. 31, n. 2, p. 251264, maio/ago, 2005.

TUNG, D.V.; PINNOI, A. Vehicle routing-scheduling for waste collection in Hanoi. European Journal of Operational Research. Brussels-BE. v. 125, n. 3, p. 449-468, Sep. 2000.

VILHENA, A.; D'ALMEIDA, M.L.O. Processamento do lixo: segregação de materiais. In: (coordenadores). Lixo municipal: manual de gerenciamento integrado. São Paulo: IPT/CEMPRE, p. 81-89, 2000.

WIENOLD, J; RECKNAGEL, S; SCHARF, H; HOPPE, M; MICHAELIS, M. Elemental analysis of printed circuit boards considering the ROHS regulations. Waste Management, 31, p.530-535, 2011. 